\title{
Modeling shoreline sand waves on the coasts of Namibia and Angola
}

\author{
Francesca RIBAS ${ }^{1}$, Albert FALQUÉS ${ }^{2}$, Niels VAN DEN BERG ${ }^{3}$ and Miquel CABALLERIA ${ }^{4}$
}

\begin{abstract}
The southwestern (SW) coast of Africa (Namibia and Angola) features long sandy beaches and a wave climate dominated by energetic swells from the Southsouthwest (SSW), therefore approaching the coast with a very high obliquity. Satellite images reveal that along that coast there are many shoreline sand waves with wavelengths ranging from 2 to $8 \mathrm{~km}$. A more detailed study, including a Fourier analysis of the shoreline position, yields the wavelengths (among this range) with the highest spectral density concentration. Also, it becomes apparent that at least some of the sand waves are dynamically active rather than being controlled by the geological setting. A morphodynamic model is used to test the hypothesis that these sand waves could emerge as free morphodynamic instabilities of the coastline due to the obliquity in wave incidence. It is found that the period of the incident water waves, $T_{p}$, is crucial to establish the tendency to stability or instability, instability increasing for decreasing period, whilst there is some discrepancy in the observed periods. Model results for $T_{p}=7-8 \mathrm{~s}$ clearly show the tendency for the coast to develop free sand waves at about $4 \mathrm{~km}$ wavelength within a few years, which migrate to the north at rates of $0.2-0.6 \mathrm{~km} \mathrm{yr}^{-1}$. For larger $T_{p}$ or steeper profiles, the coast is stable but sand waves originated by other mechanisms can propagate downdrift with little decay.
\end{abstract}

Key Words: Shoreline evolution, Shoreline sand waves, High angle wave instability, Longshore sediment transport

\section{Introduction}

Shoreline sand waves are undulations of the shoreline that can occur on worldwide coasts, typically showing length and time scales of kilometres and years, i.e., larger than the typical scales of rhythmic surf zone bars (Falqués et al., 2008, and references therein, for detailed information on surf zone bars). The undulations do not only occur in the shoreline position but the bathymetric contours also undulate with decreasing amplitude up to a certain depth. Shoreline sand waves are episodically or persistently found along various sandy coasts around the world (Bruun, 1954, Verhagen, 1989; Inman et al., 1992; Thevenot and Kraus, 1995; Gravens, 1999; Guillén et al., 1999; Stive et al., 2002; Ruessink and Jeuken, 2002; Davidson-Arnott and van Heyningen, 2003; Medellin et al., 2008; Alves, 2009).

Shoreline sand waves can be triggered by different physical mechanisms, including forcing by offshore bathymetric anomalies (Gravens, 1999) or periodic input of large quantities of sand due to inlets and rivers (Thevenot and Kraus, 1995). However, sand waves can also emerge from small irregularities of an otherwise rectilinear coast in absence of any forcing at its wavelength. This can occur if the wave climate is dominated by high-angle waves, i.e., waves with a high incidence angle relative to the shore normal, because the rectilinear coast becomes unstable (Ashton et al., 2001, Ashton and Murray 2006a; Falqués et al., 2011). We will hereinafter refer to the mechanism as high angle wave instability and to the resulting shoreline pattern as self-organized or free sand waves. The critical deep water wave angle for instability is between $45^{\circ}$ and $90^{\circ}$, value that mainly depends on the wave period and on the offshore reach of the bathymetric perturbation (i.e., the depth up to which the bathymetric contours undulate following the coastline undulation). High angle wave instability is favoured by large deep water angles, short wave periods and bathymetric perturbations reaching deepest regions. Moreover, large wave heights also increase the potential for instability. Falqués and Calvete (2005) found that the wavelength at the initial stage of sand wave formation, typically ranging between 3 and $15 \mathrm{~km}$, depends on the beach profile and on the height, period and angle of the incoming water waves. If there is a dominant wave direction sand waves migrate downdrift at hundreds of meters per year. Once formed, they can continue to grow in amplitude and wavelength, eventually developing into spits or capes at larger scales provided that the coast is

${ }^{1}$ Dr., Department of Applied Physics, Universitat Politècnica de Catalunya, Spain. E-mail: francesca.ribas@upc.edu.

2 Prof., Department of Applied Physics, Universitat Politècnica de Catalunya, Spain. E-mail: albert.falques@upc.edu.

${ }^{3}$ Dr., Department of Applied Physics, Universitat Politècnica de Catalunya, Spain. E-mail: niels@fa.upc.edu.

${ }^{4}$ Assoc. Prof., Escola Politècnica Superior, Universitat de Vic, 08500 Vic, Catalonia, Spain. E-mail: miquel.caballeria@uvic.cat

Note: The original manuscript of this paper was received in Jan. 2012. The revised version was received in Feb. 2013. Discussion open until June 2014. 
straight and uninterrupted long enough and the generating mechanism prevails sufficiently long (Ashton et al., 2001). Even if the coastline is stable because high angle waves are not dominant, the instability mechanism may significantly weaken shoreline diffusivity so that sand waves generated by other mechanisms can migrate a long time with little decay.

Comparison with observations of coastal morphology and the related wave climate provide confirmation of modeling studies according to which a rectilinear shoreline becomes unstable for a large enough wave incidence angle (Ashton and Murray, 2006b). Although there are some attempts (Medellin et al, 2009; Alves, 2009), a direct application of the instability theory is difficult because of the large length and time scales that are involved, so that it would require long term bathymetric surveys of long stretches of coast.

The southwestern (SW) coast of Africa (Namibia and Angola) features long uninterrupted sandy beaches and is exposed to energetic and very persistent oblique wave incidence from the Southsouthwest (SSW) (Elfrink et al., 2003; van Eeden et al., 2008). Consistently with the instability hypothesis, the coastline is very dynamic, advancing or retreating several hundreds of meters within a few years. Shoreline sand waves with wavelengths of $2-8 \mathrm{~km}$ and up to a few hundreds of meters of amplitude are present and even some large scale spits (length scale of tens of kilometers) have developed. The aims of the present contribution are twofold. The first one is to quantify the characteristics of the sand wave fields in Namibia and Angola. The second one is to apply a morphodynamic shoreline model to the morphological and wave conditions of the coast of Namibia and Angola to find out whether the coast is prone to the generation of free sand waves and to compare the model results with the observed sand waves.

\section{Shoreline sand waves on the southwestern coast of Africa}

\subsection{Wave climate}

The SW coast of Africa is dominated by southerly swells generated by storms in the Southern Atlantic Ocean. Offshore wave data of the coast of Namibia are obtained from various sources (Elfrink et al., 2003; van Eeden et al., 2008; Bosman and Joubert, 2008). All these studies used a global wave hindcast model to compute the mean offshore significant wave height, $H_{s}$, the peak wave period, $T_{p}$, and the wave direction. The mean $H_{s}$ is about $2 \mathrm{~m}$ and the wave direction is from SSW (Fig. 1). There is however an inconsistency in the values of $T_{p}$ because van Eeden et al. (2008) and Bosman and Joubert (2008) claim very large periods between 10 and $14 \mathrm{~s}$ whereas Elfrink et al. (2003) describe periods between 6 and $8 \mathrm{~s}$. The latter study also gave the water depth of these offshore wave data (132 m). The tidal range is approximately $1 \mathrm{~m}$ (Elfrink et al., 2003).

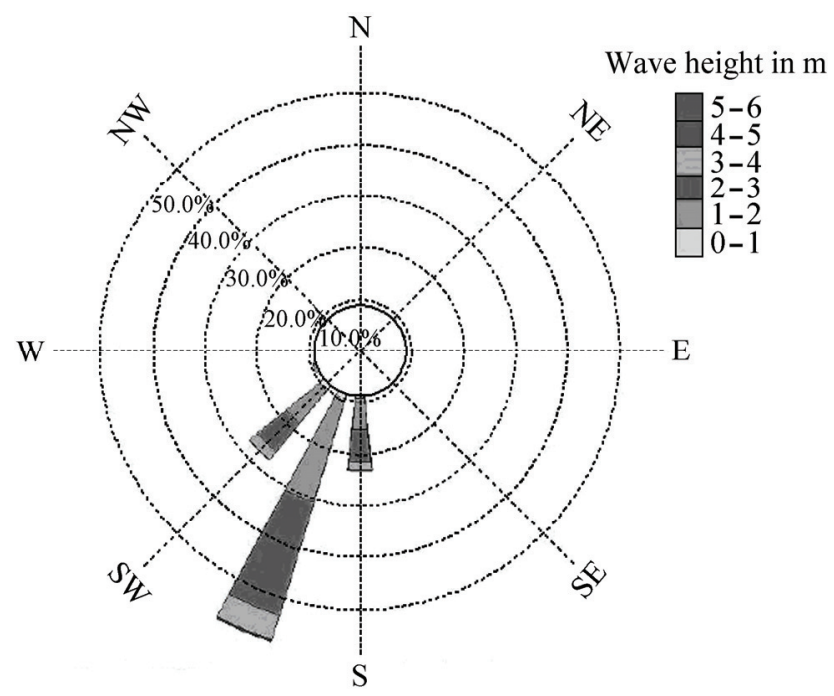

Fig. 1 Mean annual wave height rose $70 \mathrm{~km}$ offshore of the Namib coast (Bosman and Joubert , 2008)

\subsection{Studied shoreline sand wave fields}

In the present contribution we analyse part of the sandy SW coast of Africa (Fig. 2). The coast of Namibia is covered by the active dunes of the Namib Sand Sea in the south and the Cunene Sand Sea in the north, both part of the Namib Desert. The Curosa-Bahia dos Tigres sand field is located in the south of Angola. Further north, there are some long stretches of sandy coasts downdrift of river deltas. Whilst on other coasts around the world shoreline undulations can only be observed after analysis of detailed measurements of the shoreline position (Verhagen, 1989; Ruessink and Jeuken, 2002), the undulations on this African coast can be clearly observed from a quick survey of satellite images. Most striking are the large spits of Walvis Bay and Sandwich Bay and a large scale shoreline sand wave located in the north of the coast of the Namib Sand Sea (Fig. 2C). These spits resemble the flying spits described by Ashton et al. 
(2001), who related their formation to the high-angle wave instability acting over very long time periods. The study of Elfrink et al. (2003) about the evolution of the Walvis Bay spit confirmed that high-angle wave instability might play an important role on its evolution, given the highly oblique wave climate on this African coast.

A

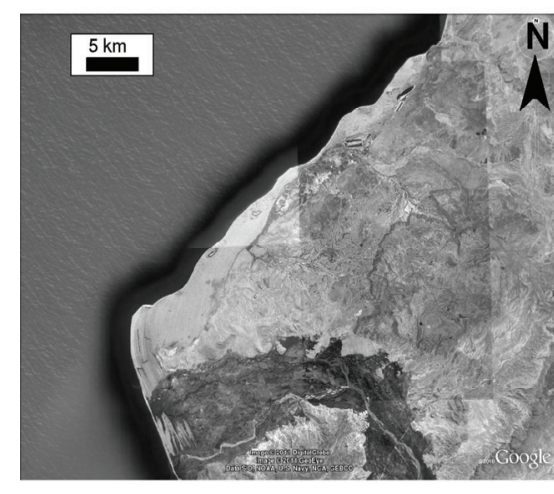

B

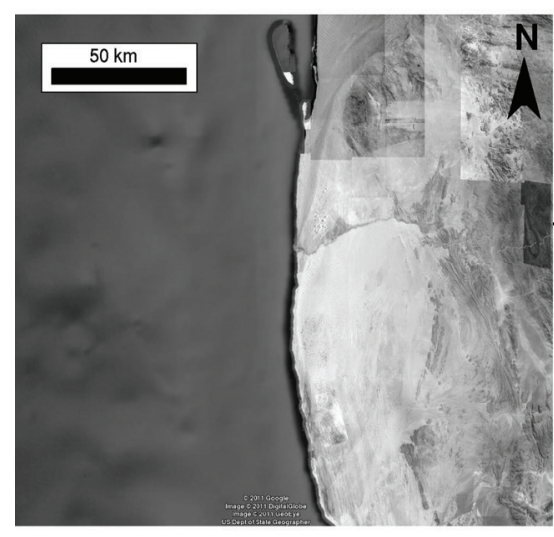

$\mathrm{C}$

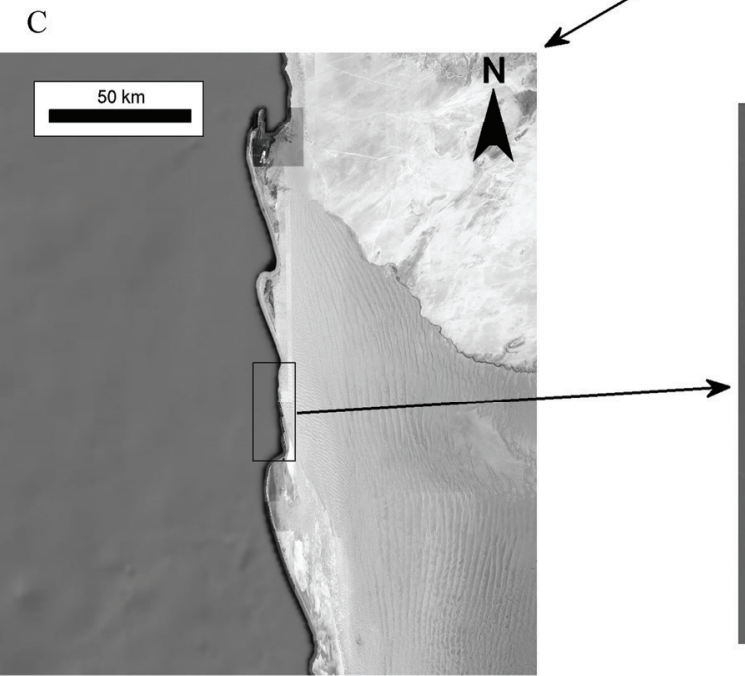

D
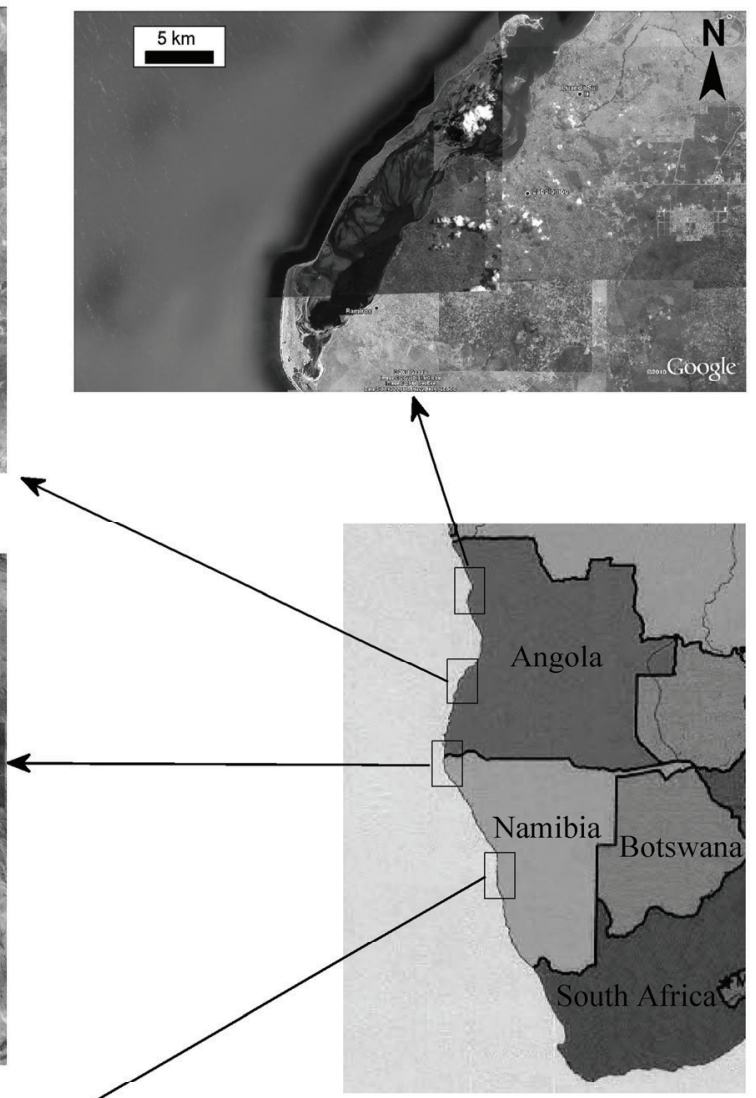

$\mathrm{E}$

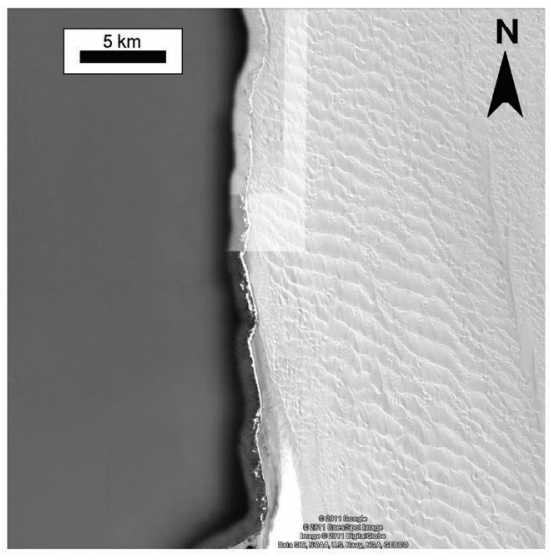

Fig. 2 The southwestern coast of Africa, including the studied sand wave fields (SWF): a) Corporolo SWF, b) Cunene SWF and Dos Tigres SWF, c) Large spits on Namib Sand Sea coast, d) Cuanza SWF, and e) Namib SWF (image source: Google Earth)

Five different sand wave fields (hereinafter referred to as SWF) with shoreline undulations at length scales of a few $\mathrm{km}$ have been selected to be analysed. The most southern one is the Namib SWF (Fig. 2E), which can be observed after zooming the Namib Sand Sea area with the large spits. It is about $30 \mathrm{~km}$ long and the orientation of the coast is roughly North-South (the clockwise angle between North and the shore normal is $270^{\circ}$ ). The second and third areas are located in the north of Namibia and the south of Angola. Given that the coastline changes orientation at S $17^{\circ} 35^{\prime} 6$ latitude, the zone was divided in two (Cunene SWF and Dos Tigres SWF, Figs. 2B and 3). The Cunene SWF is $60 \mathrm{~km}$ long and is 
orientated $259^{\circ}$ (angle from the North to the shore normal). Dos Tigres SWF is $150 \mathrm{~km}$ long, it ends at the Bahia dos Tigres flying spit and the shore-normal has a $273^{\circ}$ orientation relative to North. The fourth sand wave field (Corporolo SWF) is located further north in Angola and is not related to a coastal desert but to the Corporolo river delta (Fig. 2A). This delta provides a source of sand and the sand waves developed downdrift, where the coastline changes orientation from $238^{\circ}$ to $313^{\circ}$ (angle from the North to the shore normal). This stretch of coast is $20 \mathrm{~km} \mathrm{long}$. The last sand wave field (Cuanza SWF) is located on a $20 \mathrm{~km}$ long spit downdrift of Cuanza river delta (Fig. 2D). Just as for the previous sand wave field, the coastline changes orientation at the beginning of the spit (shore normal angle changes from $250^{\circ}$ to $318^{\circ}$, relative to North).

Because the Cuanza SWF is located on a spit it seems unlikely that there is some geological forcing on the shoreline undulations. However, satellite images show rock outcrops between the sand dunes for Cunene SWF and Dos Tigres SWF, so that the underlying geology might play a role in the shape of those coastlines. Most of the undulations, however, show an accretional wide beach at the crest and an erosional narrow beach at the downdrift though (Fig. 3). This suggests that these shoreline undulations are mainly shaped by the interaction between a sandy coastline and hydrodynamics. The same can be concluded for the Corporolo and Namib SWF because historical shorelines that reflect their evolution are visible on the beach.

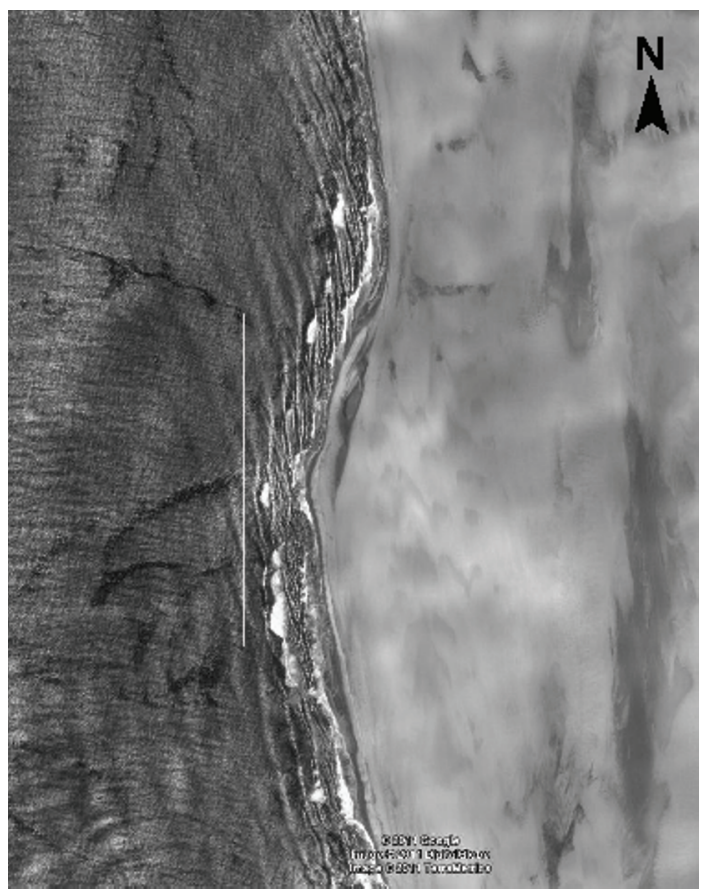

Fig. 3 Example of accretional/erosional morphology on Cunene SWF. The vertical line shows a length of $1 \mathrm{~km}$ (image source: Google Earth).

Unfortunately no bathymetric information is available for these sand wave fields. The only estimation of a cross-shore profile can be obtained from the bathymetry of the Walvis Bay spit presented in Elfrink et al. (2003).

\subsection{Wavelength and amplitude}

The shoreline position of the sand wave fields was digitized from satellite images with the use of Google Earth. Most of the coastline is covered by $2.5 \mathrm{~m}$ resolution Quickbird2 multispectral images. For the present purpose this resolution is sufficient and errors introduced by varying tidal levels and wave run-up are not important because we want to measure relatively large alongshore scale undulations in a certain moment (we do not look at the time evolution of the shoreline). The shoreline was sampled with an interval of about $100 \mathrm{~m}$. The resulting shoreline was exported and the geographic coordinates were converted to Cartesian coordinates. Subsequently the shoreline data was detrended by subtracting a mean shoreline (Fig. 4). The mean shoreline was previously obtained using an alongshore running average within a window of about $2 \mathrm{~km}$. In order to quantify the wavelength and amplitudes of the sand waves we use the definitions of Fig. 5 .

The mean amplitudes (average over all the crest and trough amplitudes) of the shoreline sand waves were estimated from the detrended shorelines (Table 1). The mean amplitude varied between 59 and $175 \mathrm{~m}$ and the largest one was found on the Coporolo SWF with $298 \mathrm{~m}$. The dominant wavelengths were determined with a Fourier analysis of the shoreline position, which gives the spectral density $\left(\mathrm{m}^{2} \mathrm{~m}^{-1}\right)$ as a function of the wavelength. The wavelength spectrum for the Namib SWF is presented in Fig. 6. It can be seen that undulations with various wavelengths coexist but that the 
dominant wavelength is about $5.8 \mathrm{~km}$. The secondary peaks are located at 2 and $2.8 \mathrm{~km}$. The dominant wavelengths of the other sand wave fields can be found in Table 1 and range between 1.5 and $7.5 \mathrm{~km}$.

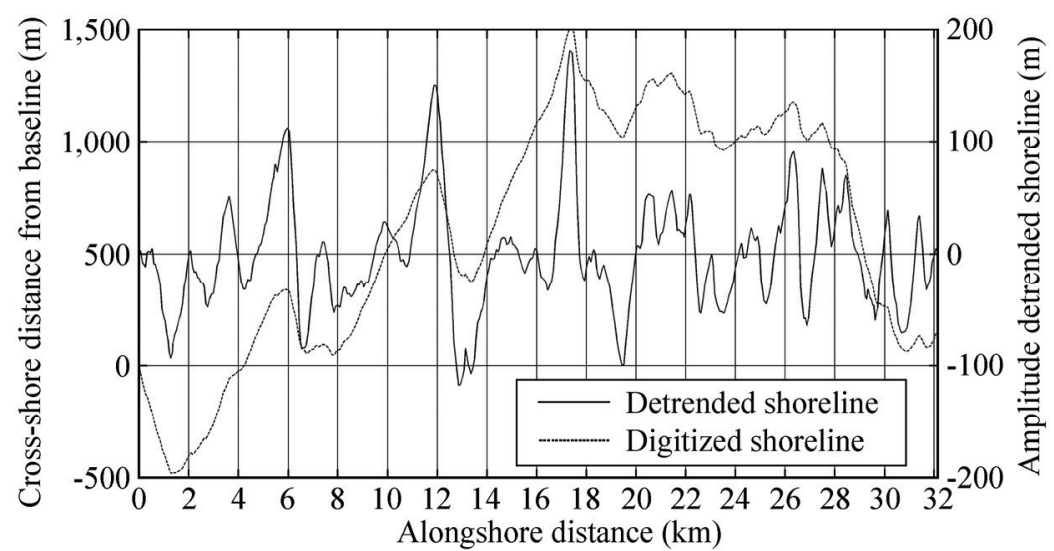

Fig. 4 Digitized and detrended shoreline of the Namib SWF

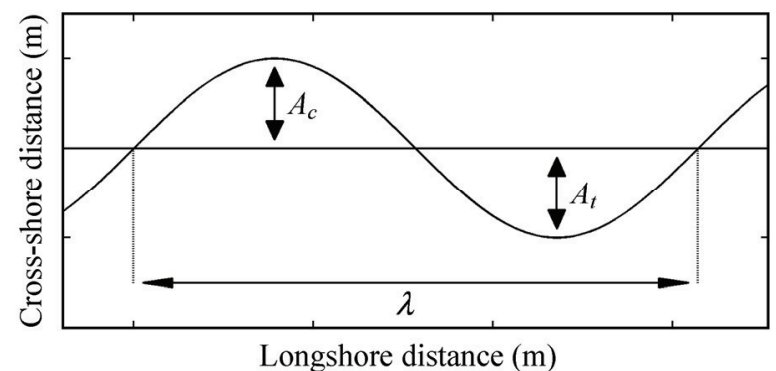

Fig. 5 Definition sketch of a shoreline sand wave, where $A_{c}$ is the amplitude of the crest, $A_{t}$ is the amplitude of the trough and $\lambda$ is the wavelength

Table 1 Amplitude and dominant wavelength for each Sand Wave Field (SWF) ${ }^{*}$

\begin{tabular}{|c|c|c|c|c|c|}
\hline SWF & $A_{\text {mean }}$ & $A_{\max }$ & $1^{\text {st }}$ peak $\lambda$ & $2^{\text {nd }}$ peak $\lambda$ & $3^{\text {rd }}$ peak $\lambda$ \\
\hline Namib & $92 \mathrm{~m}$ & $180 \mathrm{~m}$ & $5.8 \mathrm{~km}$ & $2.8 \mathrm{~km}$ & $2 \mathrm{~km}$ \\
\hline Cunene & $78 \mathrm{~m}$ & $159 \mathrm{~m}$ & $4.4 \mathrm{~km}$ & $1.5-2.7 \mathrm{~km}$ & $5.7 \mathrm{~km}$ \\
\hline Dos Tigres & $62 \mathrm{~m}$ & $200 \mathrm{~m}$ & $3.4 \mathrm{~km}$ & $7.5 \mathrm{~km}$ & $4-5 \mathrm{~km}$ \\
\hline Corporolo & $175 \mathrm{~m}$ & $298 \mathrm{~m}$ & $1.5 \mathrm{~km}$ & $3 \mathrm{~km}$ & - \\
\hline Cuanza & $59 \mathrm{~m}$ & $99 \mathrm{~m}$ & $1.9 \mathrm{~km}$ & $2.9 \mathrm{~km}$ & - \\
\hline
\end{tabular}

* $A_{\text {mean }}$ and $A_{\max }$ are the averaged and maximum amplitudes of the sand waves. The last three columns show the wavelength of the first three peaks of the Fourier analysis.

\section{Model}

In order to model the characteristics of self-organized shoreline sand waves we use the Q2D-morfo, which is a non-linear morphodynamic model for large scale shoreline dynamics. An outline of the model is given in this section omitting the details, which can be found in van den Berg et al. (2012). A Cartesian frame with horizontal coordinates $x$ and $y$ and vertical coordinate $z$ is used, where $y$ runs along the initial mean shoreline orientation, $x$ increases seaward and $z$ increases upward. The nearshore region is represented by a rectangular domain, $0<x<L_{x}$ and $0<y<L_{y}$. The unknowns are the moving shoreline, $x_{s}(y, t)$, and the changing bed level, $z_{b}(x, y, t)$. The dynamic equation for the bed level is the sediment mass conservation,

$$
\frac{\partial z_{b}}{\partial t}+\frac{\partial q_{x}}{\partial x}+\frac{\partial q_{y}}{\partial y}=0
$$

where $\left(q_{x}, q_{y}\right)$ is the depth integrated sediment flux (with bed porosity factor included). The shoreline evolution simply follows from tracking of the mesh cells with $z_{b}>0$ and the cells with $z_{b}<0$.

\subsection{Sediment transport}

The model computes the sediment transport directly from the waves, via parameterizations but without determining - 342 -

International Journal of Sediment Research, Vol. 28, No. 3, 2013, pp. 338-348 
the mean hydrodynamics, decomposing the sediment flux as

$$
\vec{q}=\vec{q}_{L}+\vec{q}_{C}+\vec{q}_{D}
$$

The first term represents the littoral drift, due to the longshore current driven by the breaking waves in case of oblique wave incidence. It is evaluated by first computing the total sediment transport rate, i.e., the cross-shore integrated flux, with the so-called generalized CERC formula (Komar, 1998),

$$
Q=\mu H_{b}^{5 / 2} \sin \left(2\left(\theta_{b}-\varphi\right)\right)
$$

where $H_{b}(y)$ is the root mean square wave height, $\theta_{b}(y)$ is the angle of wave fronts at breaking and $\varphi$ is the angle of the local shoreline, both measured clockwise from the $y$ axis. The shoreline orientation $(\varphi)$ is the mean orientation of the bathymetric contours in the surf zone rather than the orientation of the coastline itself. The empirical constant in front of $Q$ in Eq. (3) is of order $\mu=0.1-0.2 \mathrm{~m}^{1 / 2} \mathrm{~s}^{-1}$. Then, the corresponding sediment flux is computed by multiplying the total transport rate by a shape function $f(x)$ that represents the cross-shore distribution of $Q$,

$$
\vec{q}_{L}=f\left(x-x_{s}(y)\right) Q(y)(\sin \varphi(y), \cos \varphi(y))
$$

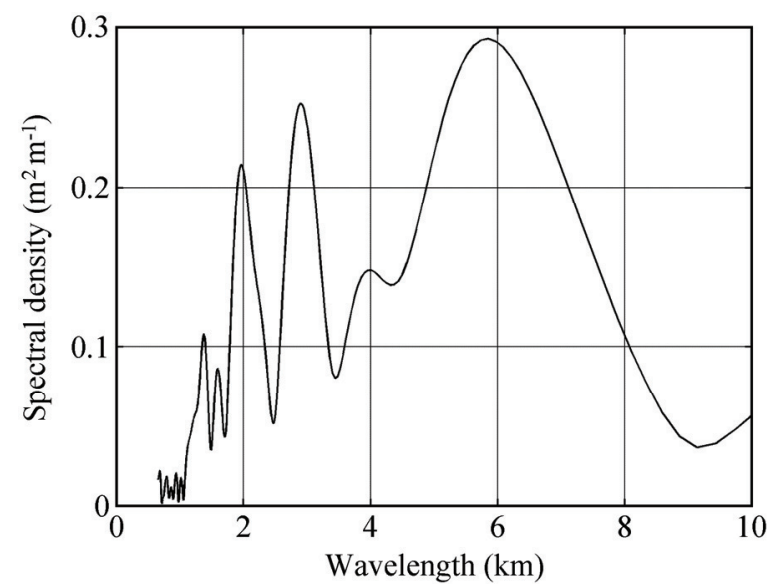

Fig. 6 Fourier analysis of the detrended shoreline of the Namib SWF, where the spectral density is plotted as a function of the wavelength

The second term in Eq. (2) is a parameterization of the down-slope transport due to gravity, onshore transport due to wave nonlinearities and offshore transport due to undertow, and it is supposed to drive the cross-shore profile to a certain equilibrium profile, that is,

$$
\vec{q}_{C}=-\gamma_{x}\left(\frac{\partial\left(z_{b}-z_{b e}\right)}{\partial x}, 0\right)
$$

where $z_{b e}(x, y)=Z\left(x-x_{s}(y)\right)$ is the assumed equilibrium profile and $\gamma_{x}$ is a cross-shore diffusivity coefficient. Finally, in order to damp subgrid processes that might cause the growth of small scale noise, diffusivity along the shoreline is added (the second term already plays this role in the cross-shore direction), characterized by an alongshore diffusivity coefficient $\gamma_{y}$,

$$
\vec{q}_{D}=-\gamma_{y}\left(\frac{\partial z_{b}}{\partial x} \sin \varphi+\frac{\partial z_{b}}{\partial y} \cos \varphi\right)(\sin \varphi, \cos \varphi)
$$

\subsection{Waves}

For the computation of the sediment transport the wave height and direction at breaking are needed. To this end a 'wave driver' is used to find the wave field in the domain from the wave input at the offshore boundary. The following equations, based on linear wave theory (Mei, 2003), are used for the present contribution,

$$
\begin{aligned}
& \omega^{2}=g k \tanh (k D) \\
& \frac{\partial(k \sin \theta)}{\partial x}=\frac{\partial(-k \cos \theta)}{\partial y} \\
& \frac{\partial}{\partial x}\left(-c_{g} H^{2} \cos \theta\right)+\frac{\partial}{\partial y}\left(c_{g} H^{2} \sin \theta\right)=0
\end{aligned}
$$

Here, the wave field is considered unidirectional, $\theta$ is the angle with respect to the $x$ axis, $H=H_{r m s}$ is the root mean square wave height, $\omega=2 \pi / T_{p}$ is the radian frequency, $k$ is the wavenumber, $c_{g}$ is the group celerity and $D=z_{s}-z_{b}$ is International Journal of Sediment Research, Vol. 28, No. 3, 2013, pp. 338-348 
the water depth. These equations are solved from deep water up to the breaking point, the latter being defined assuming $H=\gamma_{b} D$, where $\gamma_{b}$ is the saturation coefficient.

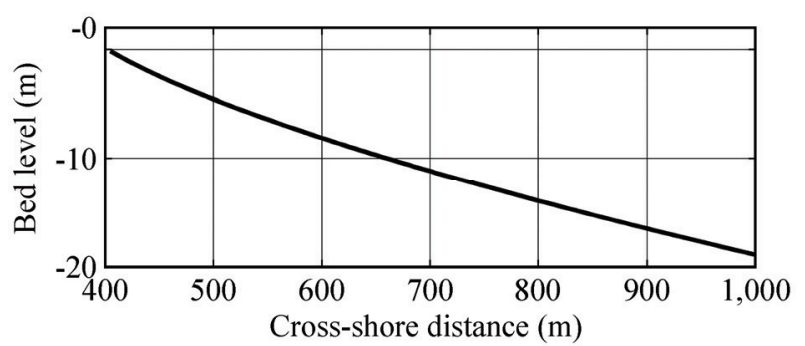

Fig. 7 Beach profile, $Z\left(x-x_{s}\right)$, of the default case study $\left(\beta=0.06\right.$ and $\left.D_{\text {ref }}=15 \mathrm{~m}\right)$

3.3 Boundary conditions and numerics

The boundary condition,

$$
\vec{q}=-\gamma_{s}\left(\frac{\partial z_{b}}{\partial x} \cos \varphi_{s}-\frac{\partial z_{b}}{\partial y} \sin \varphi_{s}+\beta\right)\left(\cos \varphi_{s},-\sin \varphi_{s}\right)
$$

is assumed at the shoreline, where $\varphi_{s}$ is the angle between the shoreline and the $y$ axis and $\gamma_{s}$ is a relaxation coefficient (i.e., the swash zone slope is assumed to relax to an equilibrium slope $\beta$ ). At the offshore boundary, $x=L_{x}$, it is assumed that the bathymetry relaxes to the equilibrium bathymetry within a certain decay distance $\lambda_{x}$ from the boundary,

$$
\frac{\partial\left(z_{b}-z_{b e}\right)}{\partial x}=-\lambda_{x}^{-1}\left(z_{b}-z_{b e}\right)
$$

Finally, at the lateral boundaries the following condition,

$$
\frac{\partial \varphi_{s}}{\partial y}= \pm \lambda_{y}^{-1} \varphi_{s}
$$

is applied, consistent with assuming an exponential decay to zero of the shoreline angle far from the domain.

The set of equations of the model is discretized in space by finite differences on a staggered grid. Equation (1) is discretized in time by a second order Adam-Bashforth explicit scheme.

\section{Model experiments}

\subsection{Parameter setup}

To test the formation of free sand waves from initial irregularities of an otherwise rectilinear coast we assume a $30 \mathrm{~km}$ long rectilinear coastline with an alongshore uniform cross-shore Dean-type profile given by

$$
Z(x)=-b\left((x+d)^{2 / 3}-d^{2 / 3}\right)
$$

where the constants $b$ and $d$ are chosen by prescribing the swash slope $\beta$ and the water depth $D_{\text {ref }}$ at an arbitrary offshore distance $x_{\text {ref }}$ (an example of profile is shown in Fig. 7). The values used for $\beta, x_{\text {ref }}$ and $D_{\text {ref }}$ were approximated from a bathymetry plotted by Elfrink et al. (2003). The cross-shore size of the simulation domain is 1,000 m, including $400 \mathrm{~m}$ of dry beach and $600 \mathrm{~m}$ of submerged beach. On top of this morphology we add a localized Gaussian-shaped bathymetric perturbation that causes an initial undulation on the shoreline position of $2 \mathrm{~km}$ alongshore width and with different amplitude values, $a$. In the default experiments $a=18 \mathrm{~m}$ and the initial bathymetric perturbation extends offshore up to $13 \mathrm{~m}$ water depth. A localized perturbation is used instead of random perturbations because instability develops faster in the former case and this makes the exploration of different conditions easier. Moreover, it has been proven that the characteristics of the emerging self-organized sand waves are independent of the initial perturbation (van den Berg, 2011; 1012). The grid size is given by $\Delta x=5 \mathrm{~m}$ and $\Delta y=50 \mathrm{~m}$, and the time step is $\Delta t=0.001$ days. The wave field is updated only once a day. Other model parameters are set to the default values described by van den Berg et al. (2011).

Several experiments have been performed to cope with the uncertainty and variability in the bathymetric and wave conditions along the SW African coast (Table 2). We consider two bathymetric profiles, one milder than the other. According to section 2 we apply a significant wave height $H_{s}=2 \mathrm{~m}$ at a water depth of $132 \mathrm{~m}$. Since the dominant wave direction in deep water is SSW and the coastline trends approximately S-N, we consider deep water wave angles in the range $65^{\circ}-75^{\circ}$. We use wave periods $T_{p}=7-12 \mathrm{~s}$, which are within the range of observed values. The offshore waves are refracted to the offshore boundary of the model by assuming rectilinear and parallel depth contours. This results in wave angles between $58^{\circ}-61^{\circ}$ at the offshore boundary. The values of various parameters corresponding to the different model runs can be found in Table 2 . 
Table 2 Parameter setup and results for the main numerical experiments ${ }^{*}$

\begin{tabular}{|c|c|c|c|c|c|c|c|c|c|}
\hline Run \# & $\beta$ & $\begin{array}{c}D_{\text {ref }} \\
(\mathrm{m})\end{array}$ & $\begin{array}{c}\theta \\
(\mathrm{deg})\end{array}$ & $\begin{array}{c}H_{\text {rms }} \\
(\mathrm{m})\end{array}$ & $\begin{array}{c}T_{p} \\
(\mathrm{~s})\end{array}$ & Tendency & $\begin{array}{c}\lambda_{m} \\
(\mathrm{~km})\end{array}$ & $\begin{array}{c}A_{m} \\
(\mathrm{~m})\end{array}$ & $\begin{array}{c}c_{m} \\
\left(\mathrm{~km} \mathrm{yr}^{-1}\right)\end{array}$ \\
\hline 1 & 0.06 & 15 & 61 & 1.10 & 8 & Instability & 3.7 & 40 & 0.30 \\
\hline 2 & 0.06 & 15 & 61 & 1.10 & 7 & Instability & 4.4 & 217 & 0.60 \\
\hline 3 & 0.06 & 15 & 61 & 1.10 & 12 & Stability & - & - & - \\
\hline 4 & 0.06 & 15 & 58 & 1.17 & 8 & Instability & 4.0 & 7.4 & 0.18 \\
\hline 5 & 0.06 & 15 & 58 & 1.10 & 7 & Instability & 3.6 & 46 & 0.25 \\
\hline 6 & 0.08 & 20 & 61 & 1.11 & 8 & Stability & - & - & - \\
\hline 7 & 0.08 & 20 & 58 & 1.17 & 8 & Stability & - & - & - \\
\hline
\end{tabular}

The parameters defining the initial profile are $\beta$ and $D_{\text {ref, }}$ and the wave characteristics at the offshore boundary of the domain are $\theta$, $H_{r m s}$ and $T_{p}$. The characteristics of the emerging sand waves are their mean wavelength, $\lambda_{m}$, amplitude, $A_{m}$, and migration rate, $c_{m}$, which are obtained by averaging those corresponding to the second and third crests and troughs of the modelled self-organized sand wave train after $16 \mathrm{yr}$.

\subsection{Model results}

The shoreline evolution of the model experiments can be characterized by i) the evolution of the initial perturbation (Fig. 8) and, ii) in case of instability, the development of a downdrift self-organized sand wave train (Figs. 9 and 10). The evolution of the perturbation can be summarized as: the initial diffusion of the Gaussian perturbation (mainly in the cross-shore direction), the downdrift migration of the crest, the development of asymmetry, and the development of a downdrift erosional zone. In case of instability, the erosional zone grows in amplitude (Fig. 8), whereas in case of stability the erosional zone amplitude starts decaying in a certain moment (Fig. 11). The formation of a self-organized sand wave train in case of instability can be summarized as: the triggering of a downdrift crest by the erosional zone, the growth of this second crest, the triggering of a second downdrift erosional zone, and so on, in such a way that a self-organized sand wave train forms (Fig. 9). From the results obtained in the experiments performed (Table 2) it is clear that the mild bathymetric profile together with wave conditions with periods of 7-8 s (i.e., runs 1, 2, 4 and 5; Fig. 9) clearly lead to instability whereas steeper profiles or large periods lead to stability (i.e., runs 3, 6 and 7; Fig. 11).

Since we want to study the self-organized or free sand waves, we are mostly interested on the characteristics of the sand wave trains emerging from process ii) in case of an unstable coast. The characteristic wavelength of the instability is that of the wave train since the length scale associated to the first crest and trough is influenced by the initial perturbation. Notice that the shape of the initial perturbation only determines the relevant length scale of process i) but not the wavelength that emerges from process ii), which is fully self-organized. This has been tested in other studies (van den Berg et al, 2011) or by using random initial conditions (van den Berget al., 2012). Here we quantify the characteristics of the free sand waves by averaging the wavelength, amplitude and migration rate obtained from the second and third crests and troughs (Table 2).

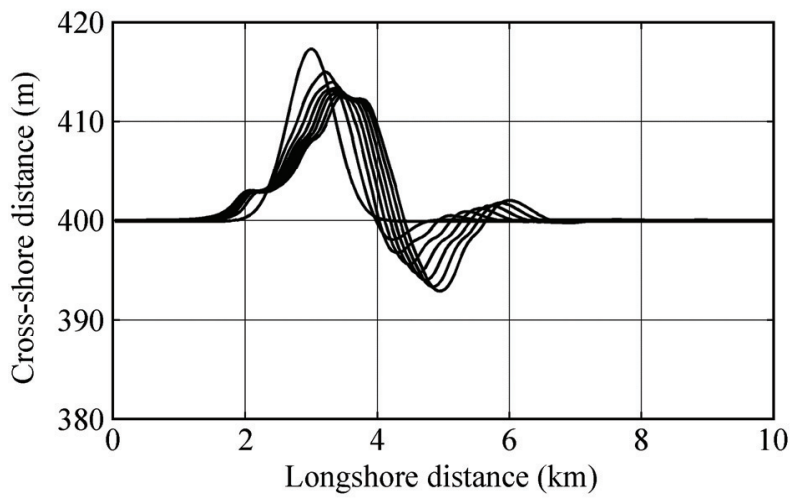

Fig. 8 Initial evolution of the shoreline for experiment 1 , from an initial Gaussian shaped perturbation at $y=3 \mathrm{~km}$. The shoreline is plotted every 50 days and the final shoreline corresponds with the result after 1 year. The wave incidence is from the left. Notice that the cross-shore distance is exaggerated a factor 150 . 


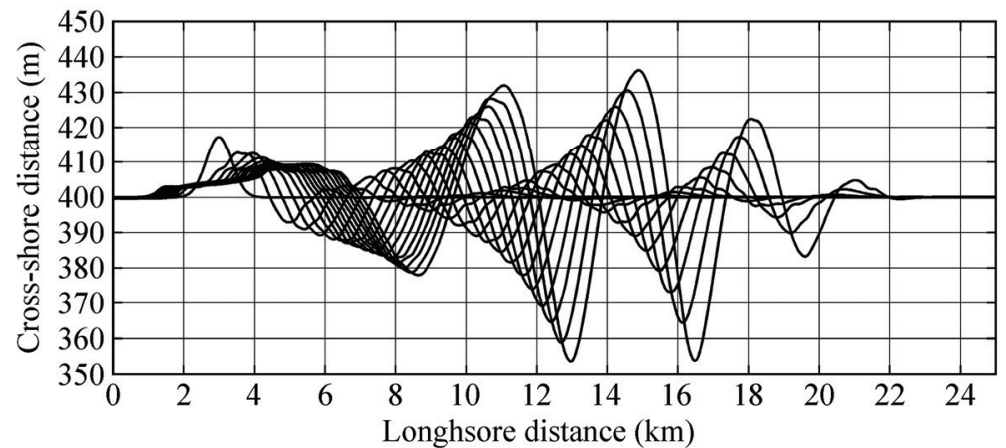

Fig. 9 Formation of the sand wave train for experiment 1, from an initial Gaussian shaped perturbation at $y=3 \mathrm{~km}$. The shoreline is plotted every year and the final shoreline corresponds with the result after 16 years. The wave incidence is from the left. Notice that the cross-shore distance is exaggerated a factor 100 .

The time scale of development of the instability (in case of an unstable coast) is of the order of several years. In the default experiment (run 1), corresponding to $T_{p}=8 \mathrm{~s}$ and $\theta=61^{\circ}$, within $16 \mathrm{yr}$ the mean amplitude of the sand waves reaches $40 \mathrm{~m}$ and the mean wavelength is $3.7 \mathrm{~km}$ (Figs. 9 and 10). At the same time, the sand waves migrate downdrift at a migration rate of $0.3 \mathrm{~km} \mathrm{yr}^{-1}$. Decreasing the period to $7 \mathrm{~s}$ (run 2), the instability becomes stronger: the mean amplitude reaches $217 \mathrm{~m}$ after $16 \mathrm{yr}$ and the migration rate increases to $0.6 \mathrm{~km} \mathrm{yr}^{-1}$. Instability weakens if $\theta$ decreases (runs 4 and 5). The wavelengths of the free sand waves do not depend strongly on the wave conditions, and range from 3.6 to $4.4 \mathrm{~km}$ after $16 \mathrm{yr}$.

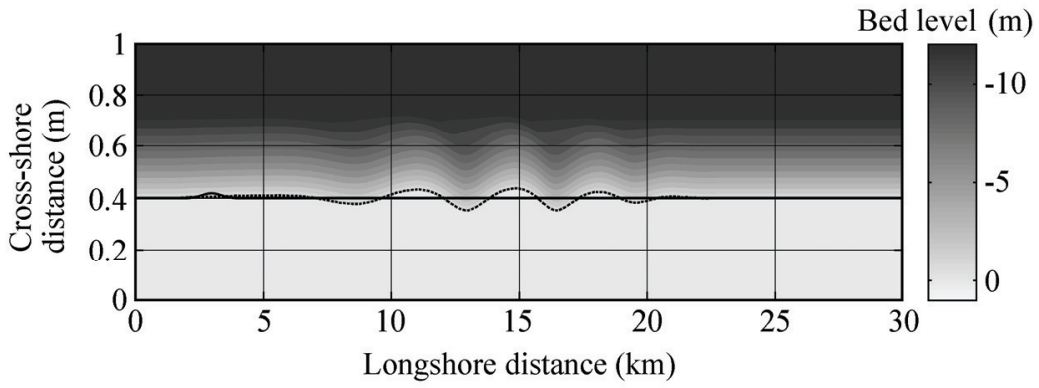

Fig. 10 Bathymetry of the sand wave train for experiment 1 after 16 years. The black solid and dashed lines indicate the initial and final shorelines, respectively. The wave incidence is from the left. There is a factor 10 exaggeration in the cross-shore direction.

Even in case of a stable coast, the coastline diffusivity (a concept defined in Falqués and Calvete, 2005) is so low that shoreline features created by other processes can persist and propagate downdrift for a long time nearly without decaying. Thus, no matter if they grow or decay, all shoreline features at these alongshore scales migrate downdrift under oblique wave incidence. This is visible, e.g., in experiment 4 (Fig. 11), where the shoreline perturbation decays but propagates at a celerity of about $0.45 \mathrm{~km} \mathrm{yr}^{-1}$.

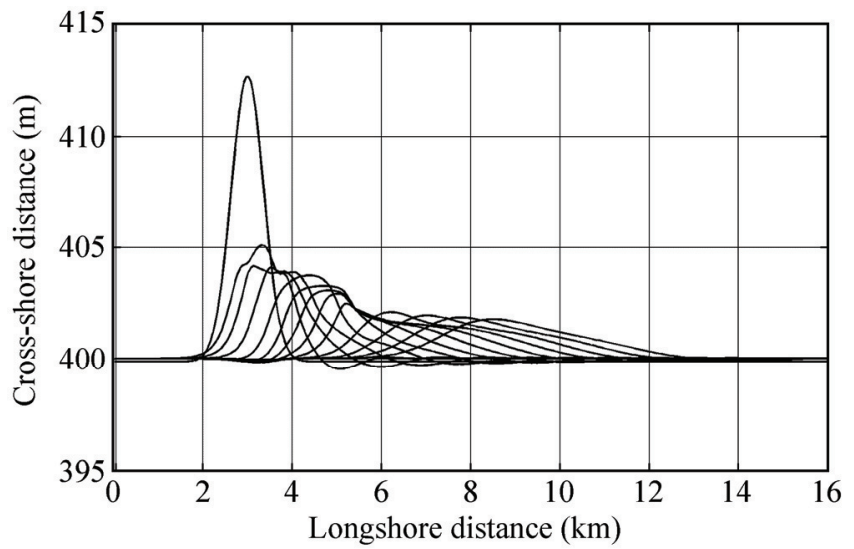

Fig. 11 Evolution of the shoreline for experiment 6, from an initial Gaussian perturbation at $y=3 \mathrm{~km}$. The shoreline is plotted every year and the final shoreline corresponds with the result after 11 years. The wave incidence is from the left. Notice that the cross-shore distance is exaggerated a factor 500. 
Model runs doubling the amplitude or the cross-shore extension of the initial perturbation have been performed (not shown). The resulting tendency to stability/instability does not change and the self-organized sand wave train in case of instability shows the same characteristics.

\section{Discussion and conclusions}

A large part of the SW coast of Africa (Namibia and Angola) is composed of long sandy beaches. Apart from large scale spits, many stretches of this coast feature smaller systematic shoreline undulations or shoreline sand waves. A Fourier analysis of the shoreline position for some sand wave fields show that several length scales coexist within the range of 1.5 and $7.5 \mathrm{~km}$. The average sand wave amplitudes range from 60 to $175 \mathrm{~m}$. Since the wave climate is dominated by incidence angles from SSW, i.e., very oblique to the coast that roughly trends S-N, the hypothesis that those shoreline features are driven by the so called high angle wave instability is very plausible. This hypothesis is also strongly supported by the fact that the wavelengths nicely overlap the linear instability range (3-15 km) for general conditions (Falqués and Calvete, 2005). Some satellite images suggest that the shoreline undulations are dynamically active (rather than controlled by the geological setting), showing erosion at the bay and deposition at the crest and a tendency to growth in downdrift direction. However rock outcrops can also be seen on the images and we cannot rule out that the underlying geology may play a role in the presence of these shoreline undulations.

Preliminary model computations have shown that, indeed, this coast has potential for instability. The factors that clearly favour instability are the high wave angles relative to the coast in deep water and that the wave climate is quite energetic (annual mean $H_{s}$ about $2 \mathrm{~m}$ ). But the factor that strongly inhibits instability are the potentially large wave periods, $T_{p} \sim 10-14 \mathrm{~s}$, since wave refraction severely reduces the angle of these long waves until they reach the morphodynamic active part of the beach profile. Unfortunately, there is no consensus among the sources of information on wave period. Elfrink et al. (2003) points out to dominant periods of $T_{p}=6-8 \mathrm{~s}$ while van Eeden et al. (2008) and Bosman and Joubert (2008) give wave periods mainly in the range $T_{p}=10-14 \mathrm{~s}$.

For $T_{p}=7-8 \mathrm{~s}$ and a relatively mild profile $(\beta=0.06)$, the model clearly predicts coastline instability and the formation of free sand waves of about $3.5-4.5 \mathrm{~km}$ wavelength, migrating at a rate of $0.2-0.6 \mathrm{~km} \mathrm{yr}^{-1}$ and reaching amplitudes up to 40-200 m within $16 \mathrm{yr}$. The modelled wavelength is in good agreement with the range of wavelengths obtained with the Fourier analysis of the various sand wave fields on the SW Africa. The variance in the wavelength of the observed sand wave fields could be related to i) alongshore variability in the underlying bathymetry as milder slope profiles lead to longer wavelengths, ii) different wave conditions along the coast or iii) transition to larger wavelengths due to long term growth and nonlinear interactions. Modelled sand wave amplitudes are also consistent with the observed ones, although we do not know when the sand waves started to form in the field. Regarding the migration rates, Elfrink et al. (2003) showed several shorelines at Donkey Bay between 1993 and 2002, from which an alongshore migration rate of the order of $0.05 \mathrm{~km} \mathrm{yr}^{-1}$ can be estimated. Thereby, the model over-predicts migration rates by an order of magnitude. For $T_{p}=12 \mathrm{~s}$ or a steeper profile $(\beta=0.08)$, the shoreline is stable. In this case, however, the coastline diffusivity (as defined in Falqués and Calvete, 2005) is very low compared to the one corresponding to the classical 1-line models (for the same beach conditions), so that coastline features created by any reason can persist and propagate to the north for a long time.

A relatively important limitation of the present study is the lack of detailed knowledge of the bathymetry. From bathymetric maps at one location we inferred the slope at the shoreline and the distance to shore of a certain bathymetric contour. From this we adjusted a Dean-type profile and we assumed that this profile was characteristic all along the whole coast. This severe simplification can have a significant influence on the results since it has been proved that the bathymetry affects the free sand wave characteristics (Calvete and Falqués, 2005).

This is just a preliminary study. Future work will focus on obtaining more detailed bathymetric data and reliable wave climate data. In particular, the discrepancy in the reported wave periods must be solved. Model computations should be done with a more accurate bathymetry of each stretch of coast and using either time series from wave records or synthetic time series of wave forcing based on the statistics given by the wave roses. This could provide a clue to why in certain stretches there are sand waves whilst in others stretches they are not found, and to why different wavelengths and amplitudes are observed at different locations.

\section{Acknowledgement}

This work has been funded by the Spanish Ministerio de Educación e Innovación, through the research project 'Modelización y monitorización integradas en morfodinámica de playas naturales y regeneradas', (contract CTM2009-11892/IMNOBE). The third author was supported by a FPI scholarship of the Spanish government within the research contract CTM2006-08875/MAR.

\section{References}

Alves A. R. 2009, Long term erosional hot spots in the southern Brazilian coast. Journal of Geophysical Research, Vol. 114, C02020, doi:10.1029/2008JC004933. 
Ashton A., Murray A. B., and Arnault O. 2001, Formation of coastline features by large-scale instabilities induced by high-angle waves. Nature, Vol. 414, pp. 296-300.

Ashton A. and Murray A. B. 2006a, High-angle wave instability and emergent shoreline shapes: 1. Modeling of sand waves, flying spits, and capes. Journal of Geophysical Research, Vol. 111, F04011, doi:10.1029/2005JF000422.

Ashton A. and Murray A. B. 2006b, High-angle wave instability and emergent shoreline shapes: 2. Wave climate analysis and comparisons to nature. Journal of Geophysical Research, Vol. 111, F04012, doi:10.1029/2005JF000423.

Bosman D. E. and Joubert J. R. 2008, Report on wave, wind and water level conditions at Wabis Bay. Technical Report Namibian Port Authority.

Bruun P. 1954, Migrating sand waves or sand humps, with special reference to investigations carried out on the Danish North Sea Coast. Coastal Engineering, ASCE, pp. 269-295.

Davidson-Arnott R. G. D. and van Heyningen A. 2003, Migration and sedimentology of longshore sandwaves, Long Point, Lake Erie, Canada. Sedimentology, Vol. 50, pp. 1123-1137.

Elfrink B., Prestedge G., Rocha C. B. M., and Juhl J. 2003, Shoreline evolution due to highly oblique incident waves at Walvis bay, Namibia. Coastal Sediments 2003, CD-rom.

Falqués A. and Calvete D. 2005, Large scale dynamics of sandy coastlines. Diffusivity and instability. Journal of Coastal Research, Vol. 110, C03007, doi:10.1029/2004JC002587.

Falqués A., Calvete D., and Ribas F. 2011, Shoreline instability due to very oblique wave incidence: Some remarks on the physics. Journal of Geophysical Research, Vol. 27, No. 2, pp. 291-295.

Falqués A., Dodd N., Garnier R., Ribas F., MacHardy L. C., Larroude P., Calvete D., and Sancho F. 2008, Rhythmic surfzone bars and morphodynamic self-organization. Coastal Engineering, Vol. 55, No. 7-8, pp. 622-641, doi:10.1016/j.coastaleng. 2007.11.012.

Gravens M. B. 1999, Periodic shoreline morphology, Fire Island, New York. Coastal Sediments, pp. 1613-1626.

Guillén J., Stive M. J. F., and Capobianco M. 1999, Shoreline evolution of the Holland coast on a decadal scale. Earth Surface Processes and Landforms, Vol. 24, pp. 517-536.

Inman D. L., Elwany M. H. S., and Khafagy A. A. 1992, Nile delta profiles and migrating sand blankets. Coastal Engineering, ASCE, pp. 3273-3284.

Komar P. D. 1988, Beach processes and sedimentation, $2^{\text {nd }}$ ed., prentice-Hcell, Upper Saddle River, N. J.

Medellín G., Medina R., Falqués A., and González M. 2008, Coastline sand waves on a low energy beach at El Puntal spit, Spain. Marine Geology, Vol. 250, pp. 143-156.

Medellín G., Falqués A., Medina R., and González M. 2009, Sand waves on a low-energy beach at El Puntal Spit, Spain: Linear stability analysis. Journal of Geophysical Research, Vol. 114, C03022, doi:10.1029/2007JC004426.

Mei, C. C. 2003, The applied dynamics of ocean surface waves, Advanced series on ocean engineering - Volume 1, published by World Scientific.

Ruessink B. G. and Jeuken M. C. J. L. 2002, Dunefoot dynamics along the Dutch coast. Earth Surface Processes and Landforms, Vol. 27, pp. 1043-1056.

Stive M. J. F., Aarninkhof S. G. J., Hamm L., Hanson H., Larson M., Wijnberg K. M., Nicholls R. J., and Capobianco M. 2002, Variability of shore and shoreline evolution. Coastal Engineering, Vol. 47, pp. 211-235.

Thevenot M. M. and Kraus N. C. 1995, Longshore sandwaves at Southampton Beach, New York: Observations and numerical simulation of their movement. Marine Geology, Vol. 126, pp. 249-269.

Van den Berg N., Falqués A., and Ribas F. 2011, Long-term evolution of nourished beaches under high angle wave conditions. J. Marine Systems, Vol. 88, pp. 102-112.

Van den Berg N., Falqués A., and Ribas F. 2012, Modeling large scale shoreline sand waves under oblique wave incidence. Journal of Geophysical Research, Vol . 117, F03019, doi:10.1029/2011JF002177.

Van Eeden F., Smith G., and van Tonder A. 2008, Walvis Bay setback line. Technical Report WSP Africa Coastal Engineers.

Verhagen H. J. 1989, Sand waves along the Dutch Coast. Coastal Engineering, Vol. 13, pp. 129-147. 